\title{
ADHD: the impact when not diagnosed
}

\author{
TDAH: o impacto da ausência do diagnóstico \\ Isabella de Souza', Paulo Mattos', Camila Pina', Didia Fortes ${ }^{1}$
}

\begin{abstract}
ADHD is a highly prevalent disorder in childhood with social, academic and familial difficulties when not diagnosed and treated correctly. The aim of this case report is to demonstrate the impairment of ADHD among generations of the same family.
\end{abstract}

\section{Keywords}

ADHD, diagnoses,

impairment.

\section{RESUMO}

O TDAH é uma doença de alta prevalência na infância, ocasionando dificuldades sociais, acadêmicas e familiares quando não diagnosticado e tratado adequadamente. O objetivo

\section{Palavras-chave}

TDAH, diagnóstico, prejuízo. desse estudo de caso é demonstrar o grave prejuízo causado pelo TDAH em três gerações de uma mesma família.

\section{INTRODUCTION}

ADHD is highly prevalent among general population and over the past decades, the interest in this diagnoses has been growing' altering dramatically the understanding of this disorder. Previously, it has been seen like a disorder limited to the childhood, but recent researches have been showing that this condition should be understood as lifelong disease in many cases, provoking serious damages to the child with ADHD. Inattentiveness compromises academic skills, resulting more failures in school setting and consequentely abandoning. Likewise, impulsiviness is responsable for risk behaviour, difficult interpersonal relationships and inaccurate conduct, carrying damage to the patient and society ${ }^{2}$. ADHD patients are often involved in traffic accidents, unemployment, divorce, face less possibilities of professional advancement and experiment chronic frustration and underachievement ${ }^{3}$.
Although the cientific evidences confirm the diagnoses validity and the treatment efficacy, some mental health professionals, erraticaly based in their personal beliefs, react with prejudice and reject the need of careful attention to this problem. With this case report we are willing to draw attention in order to show the damages caused by inattentiveness and impulsiviness in the adolescent life when the disorderr is not detected by the family. Our aim is light up the need of early diagnoses and correct treatment, avoiding so many suffering.

\section{CASE REPORT}

Fifteen year old adolescent, coursing sixth grade in primary private school was referred to evaluation at Rio de Janeiro Federal University (Geda - Attention Deficit Study Group), presenting hostile and defiant behaviour at home and school, with poor academic achievment. 
As related by her aunt, the patient has always been shy. Even during kindergarten, the teachers had reported imaturity, distraction and slow academic performance. These symptoms directed her teachers to report her failure in that grade in order to improve her performance, but her poor academic development keeps on throughout primary school. Teachers have been always complaining about her lack of commitment to school responsability, procrastination and lazyness. Even with personal mentors, the patient goes on bad marks, mainly because her lack of accomplishment and distraction.

Her low self esteem had made school experts refer her to psycopedagogy department which was unable to identify any learning disability, diagnosing emotional problems. When asked about her improper behaviour, the excuses has been a deep wish of being smart like her brothers who have been having above average marks.

During adolescence, her behaviour has become more and more defiant, troublemaking, arguing with her parents and teachers and becoming agressive when facing frustration. Her anger bursts have being strong but last shortly not presenting mood instability in a persistent way. According to these problems, her family relationship has being poor and she doesn' $t$ feel herself as someone loved.

At school, she behaves like a brat, arguing with teachers and classmates, staying among bad companions. She uses to leave home during the night without permission, lying frequentely and totally desconected of school. She had started her sexual life very early and without acknoledgment about safe sex.

The patient denies alcohol or drug use. At the age of fourteen, she had got pregnant and decided to live with her boyfriend's family. Her disorganization had driven her to be judged as lazy and careless, leading the couple to split up.

After the delivery, the patient got back to mother's house, but as the troubles between mother and daugther remained, she had been referred to live with her aunt and uncle who have stabilized life. At aunt's, her behaviour has being criticized because of not taking care of baby properly. Even though being a lovely mother, her aunt reports serious negligence in baby care causing him injuries. This behaviour drives her desperate but still unable to control the situation. Her aunt had to start assuming the responsability for the baby and it drives the girl to sadness.

Back to school, her development keeps on low and the behaviour has become worse. A careful psychiatric evaluation was done with clinical interviews conducted by a physician and semi-structured interview, P-CHIPs ${ }^{4}$. The patient attends criterias for ADHD and Conduct disorder according to DSM-IV5. Bipolar disorder, depression and anxiety were exaustively investigated as was learning disabilities but the patient do not attends criterias for these diagnoses.

Neuropsychological evaluation was performed and the patient presents normal cognitive functioning (IQ: 105).
Family history evaluation and an interview with the mother, revealed the same profile between mother and daughter. The mother refers herself as inattentive. As her report, she often interrupts activities without concluding. She had abandoned the school several times and she hadn't been able to get into journalism college. The mother shows a tendency to lie, is unable to manage her finances and changes jobs frequently for impulse. She has three children and takes care of them inaccurately.

Her relationships are confuse and disturbing, related to drug, alcohol use and legal problems. As her daughter, she had gotten pregnant during adolescence and couldn't take care of the baby. The mother refers to not having information about her daugther's father since the pregnancy.

She is anxious and impulsive but denied mood complaints. She feels sorry of losing oportunities during her entire life and worries about her daughter.

\section{DISCUSSION}

The clinical case here presented makes evident the serious devastation caused by unoticed ADHD at the right time. This report shows clinically significant lifetime impairments like school failure, family mal-adjustment and legal problems caused by untreated ADHD symptoms.

Another important point of discussion is the repetition of the same behaviour characteristics between mother and daughter, lighting up the genetic influence in ADHD expression $^{6}$ and the persistence of the impairments into adulthood. Inattentiviness causes feeling of being unable to handle situations and frequently, adolescents with ADHD tend to have relationships with others in similar conditions, what difficults social improvement. ADHD adults usually present higher lifetime rates of depression, anxiety and substance abuse. It is also consistently reported higher prevalence of antisocial personality disorder among these patients ${ }^{7-9}$. The low self-esteem interfers in different situations like coping with friends and life projects, resulting lower socioeconomic status and more interpersonal difficulties. Some data show that academic and disciplinary problems faced by children and adolescents persists into the college years. In addition, these adults are more likely to have multiple divorces and job changes ${ }^{10}$.

\section{CONCLUSION}

Clinicians who provide assessment for children and adolescents need to be updated about the complexities of this diagnoses, comorbidities and difficulties faced by these patients. Moreover, they must be aware of impairments caused by untreated ADHD. 
The early accurate diagnoses could have change significantly mother, daugther and baby's lives.

\section{REFERENCES}

1. Pliszka S, Carlson C, Swanson J. ADHD with comorbid disorders, clinical assessment and management. New York: TheGuilford Press; 1999.

2. Faraone SV, Biederman J, Monuteaux MC. Toward guidelines for pedigree selection in genetic studies of attention deficit hyperactivity disorder. Genet Epidemiol. 2000;18:1-16.

3. Barkley R, Murphy K, Kwasnik D. Motor vehicle driving competencies and risks in teens and young adults with attention - deficit hyperactivity disorder. Pediatrics. 1996;98:1089-95.

4. American Psychiatry Association. Diagnostic and Statistical Manual of Mental Disorders. 4. ed. Washington D.C.: American Sychiatric Association; 1994.
5. Weller EB, Weller RA, Rooney MT, Fristad M. Children's Interview for psychiatric syndromes. Parent version (P-CHIPS). Washington DC: American Psychiatric Press; 1999.

6. Faraone SV, Biederman J, Spencer T, Wilens T, Seidman L, Mick E, et al. Attention - deficit hyperactivity disorder in adults: an overview. Biol Psychiatry. 2000;48:9-20.

7. Biederman J, Newcorn J, Sprich S. Comorbidity of attention deficit hyperactivity disorder with conduct, depressive, anxiety, and other disorders. Am J Psychiatry. 1991;148: 564- 77.

8. Biederman J, Faraone SV, Spencer T, Wilens T, Norman D, Lapey KA, et al. Patterns of psychiatric comorbidity, cognition, and psychological functioning in adults with attention deficit hyperactivity disorder. Am J Psychiatry. 1993;150:1792-8.

9. Biederman J, Wilens T, Mick E, Milberger S, Spencer T, Faraone S. Psychoactive substance use disorder in adults with attention deficit hyperactivity disorder: effects of ADHD and psychiatric comorbidity. Am J Psychiatry. 1995;152:1652-8.

10. Barkley R, Murphy K, Kwasnik D. Psychological adjustment and adaptive impairments in young adults with ADHD. J Atten Disord. 1996;1:41-54. 